\title{
Engaging Citizens in Cultural Planning with a Web Map Survey
}

\author{
Pilvi Nummi \\ Tuija Tzoulas \\ Municipality of Sipoo, Finland
}

\begin{abstract}
This article discusses the use of a web map survey tool for cultural mapping in Nikkilä, in the municipality of Sipoo, Finland. Nikkilä has in place an ongoing cultural planning and development process that involves collaborative planning between the municipal urban planning department and the cultural department. Cultural planning is a culturally sensitive approach in urban development. The main goal in cultural planning is to study 'sense of place' and discover what makes the place distinctive. The starting point of the process is to study the experiences and visions of local inhabitants and other public stakeholders regarding the area and its resources. Cultural mapping is a central part of a process that aims to increase the welfare and attractiveness of Nikkilä by utilizing existing cultural resources. This paper describes the participative design process of the web map survey, which was used as a cultural mapping tool to engage citizens to participate in the cultural planning process. Based on the case study, we are convinced that a web map survey is suitable for use as a cultural mapping tool. However, to achieve a good result it is necessary to invest in the design as well as the marketing of the survey. User-centred methods, such as collaborative planning, can be used to engage different user groups in the design of the survey. The earlier that prospective respondents can be involved in the collaborative design of a survey, the better results can be expected, quantitative as well as qualitative.
\end{abstract}

Keywords: web map survey, cultural mapping, citizen participation, public participation geographic information systems (PPGIS)

Résumé : Cet article discute de l'introduction d'outils de cartographie web dans le cadre de la planification culturelle de Nikkilä, dans la municipalité de Sipoo en Finlande. La zone de Nikkilä a depuis longtemps mis en place un processus de planification culturelle en collaboration avec le Département de planification urbaine et le Département de la culture. La planification culturelle est une activité sensible dont l'objectif principal consiste à cerner ce qui participe à l'identité d'un espace de la ville, et permettant de relever ce qui lui confère son caractère distinct. Pour Nikkilä, la planification culturelle permet de mettre en lien les

Pilvi Nummi is an Architect and Urban Planner: Municipality of Sipoo, Development and City Planning Centre, Sipoo, Finland, and a postgraduate student in Aalto University, School of Arts, Design and Architecture, Department of Architecture, Finland, E-mail: pilvi.nummi@aalto.fi. Tuija Tzoulas is a GIS engineer: Municipality of Sipoo, Development and City Planning Centre, Sipoo, Finland, E-mail: tuija.tzoulas@sipoo.fi.

Culture and Local Governance / Culture et gouvernance locale, vol. 5, no. 1-2, 2015. ISSN 1911-7469

(C) Centre on Governance, University of Ottawa, 55 Laurier Avenue East, Ottawa, Ontario, Canada K1N 6N5 
ressources culturelles disponibles afin de rendre la région plus attractive. Cet article met en relief l'utilisation des nouveaux outils web de planification culturelle et leur utilisation dans le cadre de projets de design culturel participatif. L'étude de cas démontre l'utilité de ces nouveaux outils de planification culturelle. De plus, cet article rappel l'importance du design et du marketing pour le succès de l'application des nouveaux outils de planification en ligne.

Mots clé : carte topographique en ligne, cartographie culturelle, participation du citoyen, systèmes d'information géographique publics et participatifs

\section{Introduction}

Cultural planning is an approach to participatory urban planning in which cultural resources are placed in the centre of the planning process. The method is often used in communities or urban areas that are in a state of intense change, such as when an important industry or other form of economic activity comes to an end. Cultural planning takes a broad view of culture: it covers not only art, but also such aspects of the everyday life of individuals and communities, as well as social interaction, activities, and events. Factors often associated with cultural planning are the creative industries, cultural and creative diversity, quality of the environment, and quality of life (Mercer 2006).

Within the process of cultural planning, cultural mapping denotes the gathering of data concerning the distinctive characteristics and cultural resources of an area. The local community, comprising local residents and other local actors (e.g., local entrepreneurs, employees, and the socalled third sector: local associations and other non-profit organizations), plays a central role in the identification of these resources. Cultural resources can be elements of the physical environment, such as places and landmarks that are considered important, or functional spaces, such as libraries or meeting places. Cultural mapping also covers experiences, memories, values, and opinions (Mercer 2006).

In this article, we examine the integration of cultural planning into participatory urban planning and the development of the attractiveness of a settlement in southern Finland. Participatory urban planning has increased in Finland significantly since the adoption of the Land Use and Building Act in 2000 (Finlex 1999). The Act requires that residents be given an opportunity to participate in the planning and land use of their own living environment. In practice, however, the requirement has led to a planning process in which participation takes place at a rather late stage, and mostly consists of giving feedback on existing plans. However, methods of early participation are emerging to complement official participatory land use planning practices. Cultural planning is one way of engaging local residents at an early stage of the planning process, prior to the actual land use planning process. Based on our experiences from the urban planning field, cultural planning is a new practice in Finland.

\section{Participatory urban planning vs. cultural planning}

The traditions and practices of urban planning rely heavily on the expertise of planners and on mapbased work. Participatory urban planning in its current form is therefore very much place-based, and interaction mostly consists of evaluating drawn-up plans. In other words, participation focuses 
predominantly on issues defined by the administration and planners and can be characterized as a top-down approach. Unlike in standard participatory planning practices, cultural planning must be seen as a citizen-driven process in which the goals of planning are defined in collaboration with participants. The main focus of this process is not a physical location, but the people and activities related to it. Moreover, cultural planning is implemented at an earlier stage: it is carried out before any plans for the area have yet been made.

\section{New perspective to public participation geographic information systems (PPGIS)}

Among the key benefits of web-based participation is that it involves a broader group of participants and promotes the accessibility and transparency of information and decision-making. An online process enables participation and interaction regardless of place or time (Kahila \& Kyttä 2009). In our research, the Internet is a tool that enables residents to participate in cultural mapping. On a general level, the Internet should be seen as a broader factor in urban planning, as an operating environment rather than an instrument. At best, the Internet serves as a meeting place for different communities, and enables the construction of shared knowledge (Staffans et al. 2010).

Our research contributes to the research and development of public participation geographic information systems (PPGIS) by introducing a new perspective on map surveys: the context of cultural mapping. PPGIS tools have been developed internationally for more than ten years. In Finland, pioneering research in the area of map surveys has been done by developing a survey interface known as SoftGIS (Kahila \& Kyttä 2009). In this case study, we used another similar type of map survey tool, called Harava.

The Nikkilä survey contributed to the ongoing national Action Programme on eServices and eDemocracy (SADe) by testing the use of the map-based survey tool, Harava. Coordinated by the Ministry of Finance, the SADe programme aims at creating cost-effective electronic tools to promote interaction between citizens and the public sector. The Harava tool is described as follows: "Enquiry service Harava represents one form of a PPGIS application: a map-based feedback system for collecting citizens' experiences. With Harava, organizations are able to conduct structured surveys to gain a wider perspective in decision-making" (Vartiainen et al. 2013, p. 1281).

\section{Cultural mapping in the village of Nikkilä}

Our paper presents a case study from the village of Nikkilä in the municipality of Sipoo, where we conducted a web-based map survey to gather data for cultural mapping of the area. The survey was designed to chart the perceptions and experiences of locals with regard to Nikkilä and the future development of the village. In keeping with the cultural planning method, the survey was designed to identify cultural resources and development areas in Nikkilä.

The cultural mapping survey is part of the ongoing Nikkilän Kulttuurikäytävä ('Cultural Corridor') project. Conducted by the Sipoo Centre for Development and Land Use Planning in collaboration with the municipal Cultural Services Department, the long-term project aims to promote the attractiveness of Nikkilä and the well-being of its residents using cultural means. Launched in 2010, the project brings together participation, art, culture, and local development. Cultural planning in Sipoo is seen as a method for resident-oriented cross-sectoral collaboration in which culture and art occupy a special place in the promotion of the vitality of the local community. 
The cultural mapping of Nikkilä made use of several methods, such as art exhibitions, seminars, and workshops. The main instrument in mapping this local perspective was nevertheless the map survey discussed in this paper, and the geographic information gathered with it.

The starting point of cultural planning is to engage local residents in planning as proactive subjects instead of passive objects (Mercer 2006). The goal of the cultural planning project is to introduce bottom-up thinking into municipal activities by involving stakeholders in the planning process. A similar type of cultural planning has been applied in Malmö in Sweden (Bianchini \& Ghilardi 2007). The data gathered in the survey in Nikkilä will be used in the preparation of an art policy for Nikkilä, in revisions to its development aims, and in land use projects.

\section{Research questions, methods, and data}

In this study, we adopted the principles of action research (Kindon, Pain \& Kesby 2007). We participated personally in the Cultural Corridor project by implementing a web-based map survey and also conducting interactive workshops during the development of the map survey.

The research data comprises experiences and results from the workshops organized during the development of the map survey. Two workshops were conducted to gather data about the views of the participants to help plan the web map survey. The data includes video and sound recordings of the summaries of teamwork assignments in the workshops, as well as prototypes of the map survey at its different stages. At a third interactive event, we also conducted a beta testing session to acquire feedback from prototype testers on the functionality of the map survey. In keeping with the principles of action research, our own personal experiences of the process are also used as research data.

The data also includes the responses to the final map survey. They will be used to evaluate the suitability of the content of the survey, and the representativeness of respondents. The main research questions were:

- Is a map survey a functional and useful tool for cultural mapping?

- What type of a survey best supports the mapping of cultural resources and development areas in Nikkilä?

- How can the content of a map survey be planned in collaboration with local residents?

\section{Cultural Mapping in Nikkilä, Sipoo}

\section{Nikkilä village - a developing settlement}

Sipoo is a rural municipality, although it is situated adjacent to the metropolitan area of the capital, Helsinki. The municipality has currently about 19,000 inhabitants, and vigorous population growth is expected in the next few decades. As the administrative centre of Sipoo, Nikkilä will receive its share of the growth of the capital area. The future growth of Nikkilä is by no means a given, however, and requires investment in urban and land use planning.

Nikkilä developed into an urban area in the early twentieth century, when a psychiatric hospital was built there. Many old locals remember with nostalgia the turn of the 1940s and 1950s in Nikkilä and the many municipal services they had then. The closing of the hospital in 1999 had a deep impact of the vitality of the village: the number of residents as well as visitors to the village dropped 
significantly. Now revitalization is sought by attracting new residents. The former hospital area (Itäinen Jokipuisto) has largely been converted into apartments. New residential areas are being planned to the north and east of the centre of Nikkilä. The population of Nikkilä is expected to double by 2025 from the current total of approximately 4,400 inhabitants.

Nikkilä is thus in the process of a major transition, which, it is hoped, will lead to a new boom period for the area. In the face of imminent change, municipal land use planners wished to understand how local residents see Nikkilä as it is today. For current as well as future residents, it is important that their well-being and the attractiveness of their living environment are taken into account in planning. Because of such considerations, cultural planning seemed a suitable method for approaching the question of the future development of Nikkilä. According to Ghilardi (2011) there are examples from around Europe of towns and cities that have been developed through the use of cultural resources. Areas where the special characteristics of the place are taken into consideration in development have generally been more successful than those where they have not (Bianchini \& Ghilardi 2007).

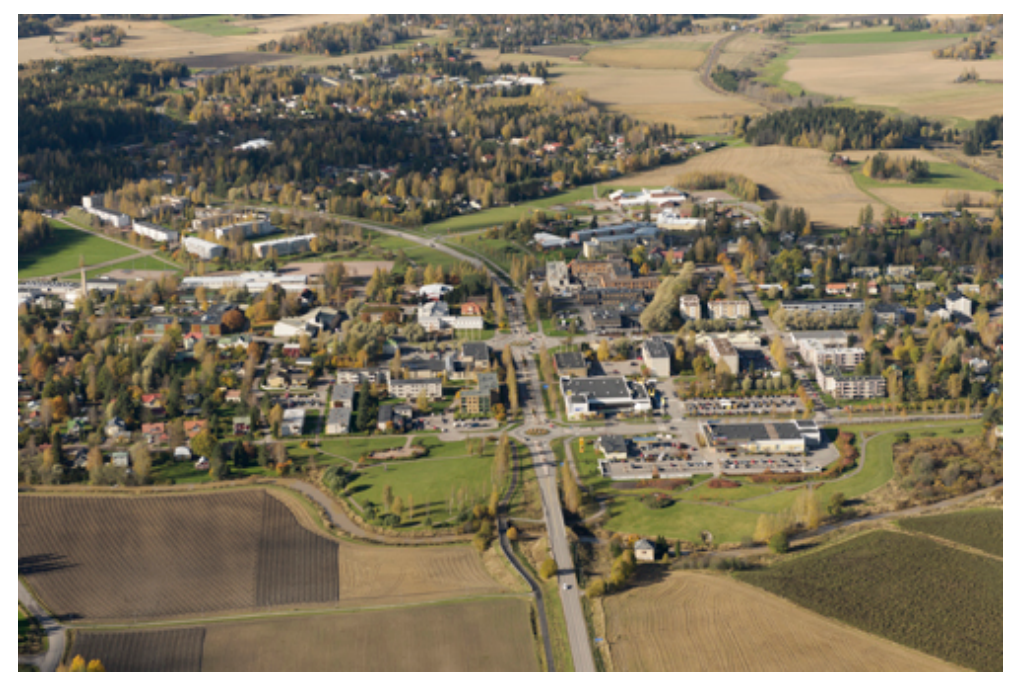

Figure 1. Aerial view of Nikkilä. The village is located in a beautiful agricultural landscape. Source: Municipality of Sipoo

\section{Distinctive features of Nikkilä}

Sipoo is a bilingual municipality: of the approximately 4,400 inhabitants in Nikkilä, the percentage of Finnish speaking inhabitants is 64\%, with most of the rest having Swedish as their first language. Only $4 \%$ has other than Finnish or Swedish as their first language. The age distribution of the Nikkilä population is shown in Figure 2. It shows that the population is quite diverse: on one hand, there are young families with school-aged children (19\% of inhabitants are under the age of 15). On the other hand, many older residents are retired from work (18\% are aged 66 years or over). 


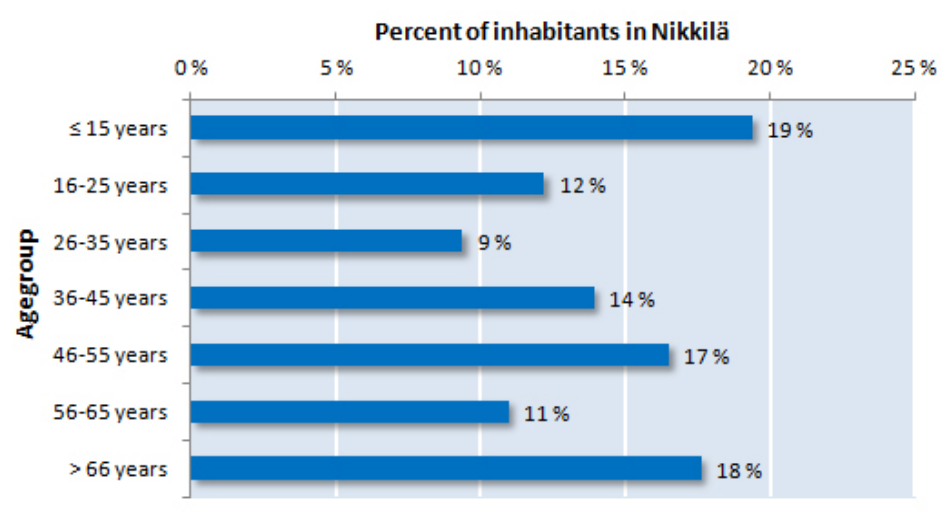

Figure 2. Age groups of inhabitants in Nikkilä. Source: Statistics Finland 2013 and Municipality of Sipoo

The Finland-Swedish identity is quite solid in Sipoo, and bilingualism is a resource that locals wish to maintain. The social climate in Nikkilä has been affected considerably by the presence of the former psychiatric hospital. When the hospital was in operation, patients were a regular sight in the centre of the village, and the residents were used to 'different' people. The mood in Nikkilä remains tolerant to this day.

As a residential area, Nikkilä is dominated by single-family housing. Most locals live in a house of their own; there are multi-storey residential houses only in the centre of the village and in the former hospital area. The typical view in Nikkilä is dominated by the surrounding cultural landscape: fields of corn that remain under cultivation. An old medieval church from the fifteenth century is today accompanied by a more recent church, built in the nineteenth century. Both churches are architecturally valuable sites.

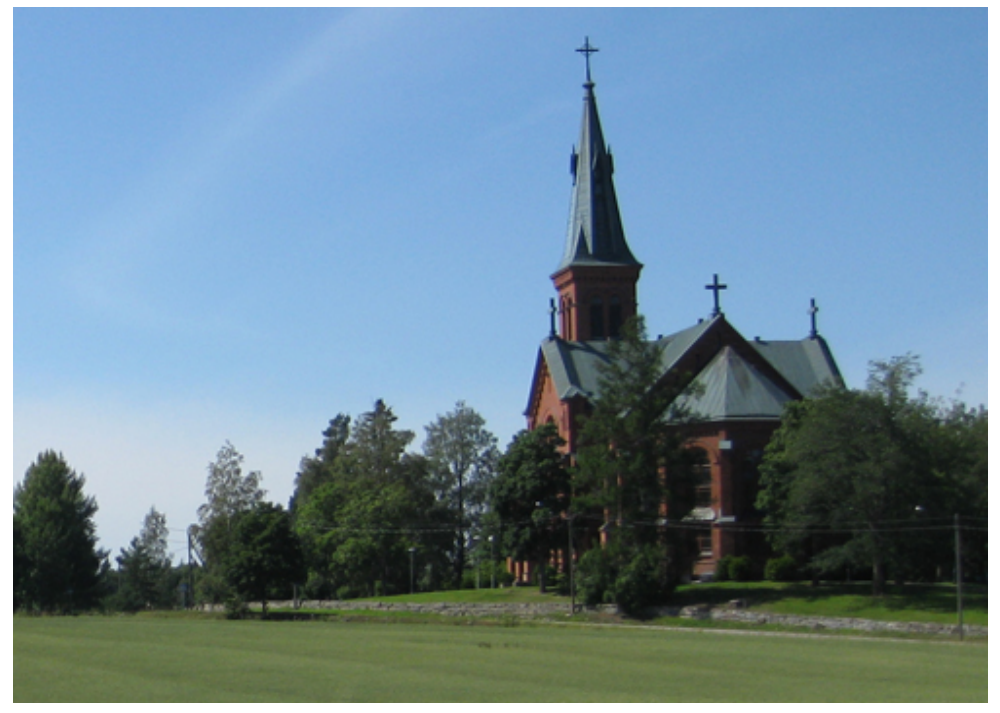

Figure 3. Nikkilä church from the nineteenth century. The village is surrounded by a rural cultural landscape. Source: Municipality of Sipoo 


\section{Collaborative development of the web map survey}

The hallmarks of cultural mapping include a solid focus on citizens and a bottom-up approach. As a method, a survey represents a fundamentally opposite, top-down approach, in which residents are objects of study instead of proactive participants or partners in interaction. In our research, we sought to conduct the survey in the spirit of the cultural planning method, engaging in a more citizen-oriented interaction with local residents. Therefore, we involved local residents in the planning of the survey at as early a stage as possible.

The planning of the survey was launched in April 2013 with a workshop whose participants included representatives of municipal government as well as Nikkilä residents. They were divided into groups to discuss what was important in Nikkilä and its future development. We developed a new teamwork method for the workshop, a kind of planning game to inspire discussion through the use of thematic and picture cards. The participants experienced the planning game as inspiring, and it helped us direct discussion at an early stage towards desired issues.

The workshop results suggested that important themes for Nikkilä are meeting places, activities and events, and the appearance of the environment, such as buildings and views. The map survey was drawn up on the basis of these results and, in addition to the above themes, the survey also covered the image of Nikkilä and important (pleasant or unpleasant) pathways that people use in their everyday life. Interactive development made the survey more locally oriented. It also facilitated the formulation of survey questions and improved the relevancy of the survey.

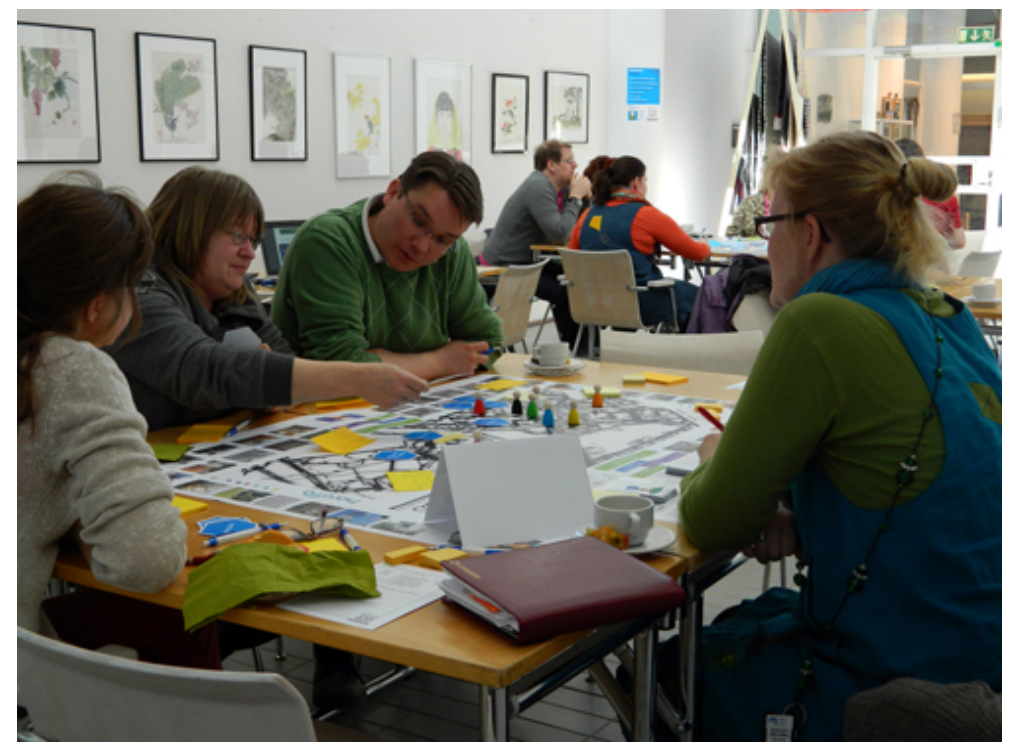

Figure 4. The planning of the survey was preceded by a workshop in which a group of local residents and representatives of municipal government discussed themes important for Nikkilä. Source: Municipality of Sipoo 


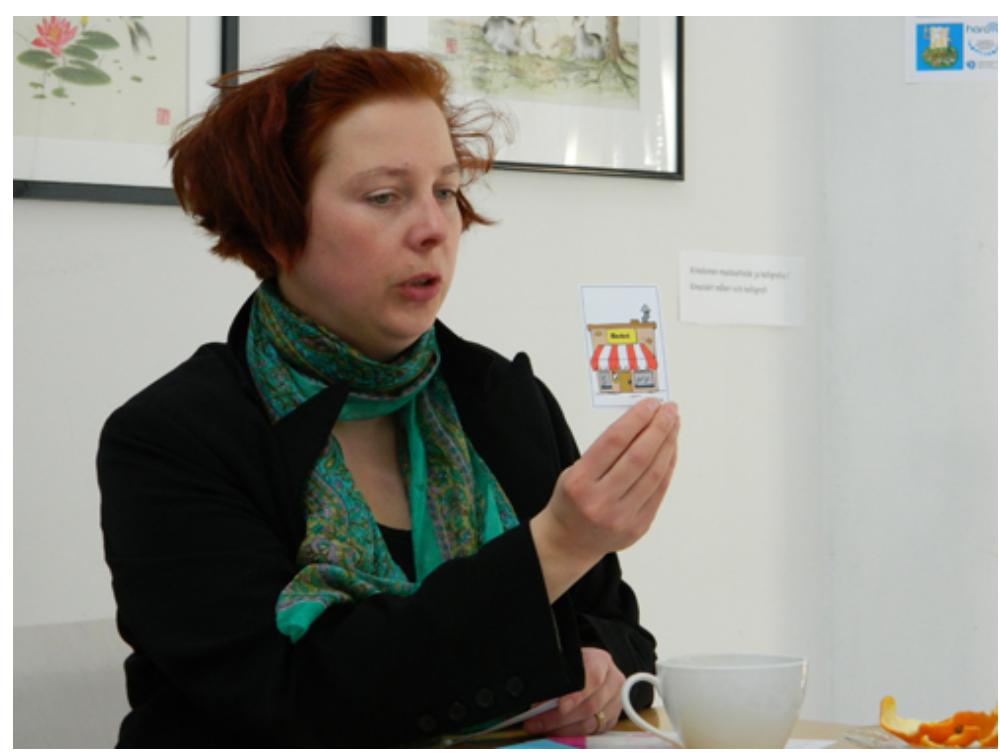

Figure 5. The planning game: Picture and theme cards were used to inspire participants to discuss themes important for Nikkilä. Source: Municipality of Sipoo



Figure 6. Screen capture of the Harava survey. In the Nikkilä study, the views and experiences of local residents on the landscapes, buildings, meeting places, activities and events, pathways, and image-related matters in Nikkilä were located on a map. Source: www.eharava.fi, Dimenteq Oy

Local residents also participated in the development of the survey by testing its functionality. Prior to putting the survey online, an event was organised at Nikkilä library where we had a functional beta version of the survey. We received feedback from the testers on the usability of the service and the formulation of the questions, among other issues. All necessary alterations were 
made to the survey before the final launch. Because we were not responsible for the development of the survey tool itself (Harava), the tool's usability problems could not be corrected at this stage. However, all problems were reported to the developer of the Harava survey tool, and will influence further development of the tool.

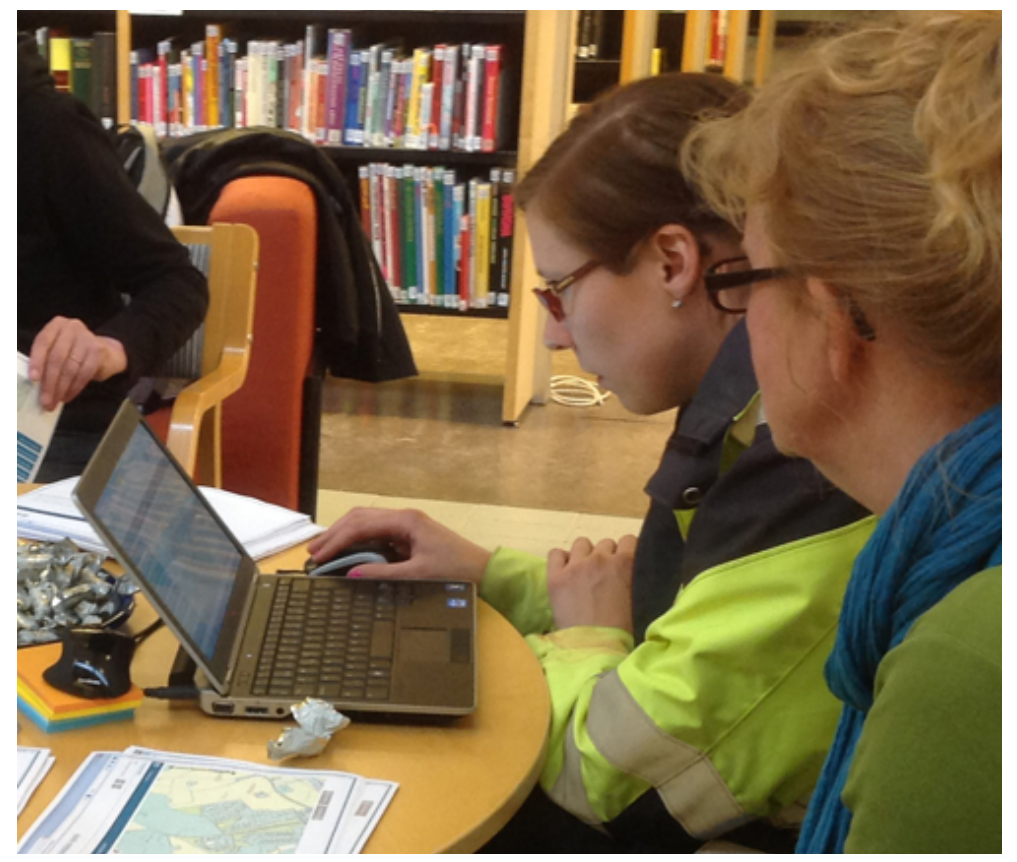

Figure 7. Eight active locals came to Nikkilä library to test the survey before it was launched. Source: Municipality of Sipoo

The survey remained online from the beginning of June to the end of September 2013. In addition to traditional marketing channels, the Internet, and newspapers, we also sent an invitation with free delivery mail to the homes of all locals in Sipoo. The launch of the survey in Nikkilä library at the beginning of June, the events organized in the planning stage, the survey planning workshop, and the beta testing increased awareness of the survey and willingness to respond. In early autumn, the survey was also advertised in schools. It was rewarding to receive responses from school pupils, which balanced the age distribution of the survey.

Interaction between stakeholders continued throughout the entire process, including the analysis stage. Locals participated in the analysis of the survey results for the first time at Nikkilä farmers' market in August 2013. Held annually in the late summer, the market draws dozens of small entrepreneurs to Nikkilä for one day to sell their produce. We participated in the market by presenting preliminary results of the survey and discussing them with locals who stopped by our stand. Concurrently, our analysis maps were displayed in the Nikkilä library at the "Nikkilä - mon amour" exhibition, a collaborative production by our Cultural Corridor project and photographer Nina Sivén. Both occasions showed that graphical maps of survey results serve as excellent discussion openers. 



Figures 8 and 9. Preliminary survey results were presented at a farmers' market in Nikkilä. Passers-by perused the maps and made their own markings on them. Source: Municipality of Sipoo

\section{Results}

We received more than 600 responses, and a total of about 3,400 location markings. Proportional to the population of Nikkilä (approximately 4,400 inhabitants), the response rate was about $15 \%$. This was an excellent result for a locality the size of Nikkilä, and likely due to active marketing of the survey. The survey was marketed throughout the entire Municipality of Sipoo, and responses were also received from locations outside the village of Nikkilä. However, the respondents were a fairly good sample of the inhabitants of Nikkilä. The distribution of first language speakers corresponded exactly with the distribution in Nikkilä. The majority of respondents lived in single-family houses and were from families of two adults. As usual in online surveys, the age distribution had a slight predominance of young people. Different methods are needed to reach older residents. In our case study, we offered a paper version of the survey to those who could not use the web-based survey.

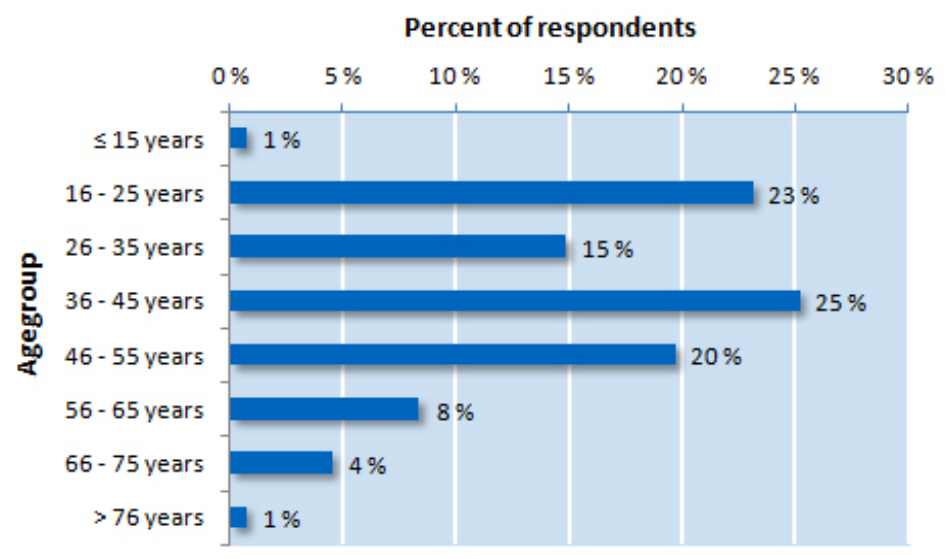

Figure 10. The age distribution of the survey respondents. Source: Municipality of Sipoo

We used the results to produce analysis maps that cover the entire locality, as well as more detailed maps on smaller areas. The broader analyses are fairly sweeping and allow the inclusion of 
hardly any detailed comments. Through geographic information analysis, we were able to discover which sites had received the most comment points, and also to illustrate places that were perceived as pleasant in terms of the landscape or buildings, as well as those places important for the image of Nikkilä. Such thematic maps give a general idea of the locals' perception of the entire area for strategic planning and development purposes.

In order to identify cultural resources and development areas, the survey included a broad range of sites that are significant for local residents, that is, places and pathways they regard as pleasant or unpleasant. In our study, cultural resources are places that attracted a particularly high concentration of positive designations, whereas development areas are those that attracted a high concentration of negative comments or suggestions for improvement.

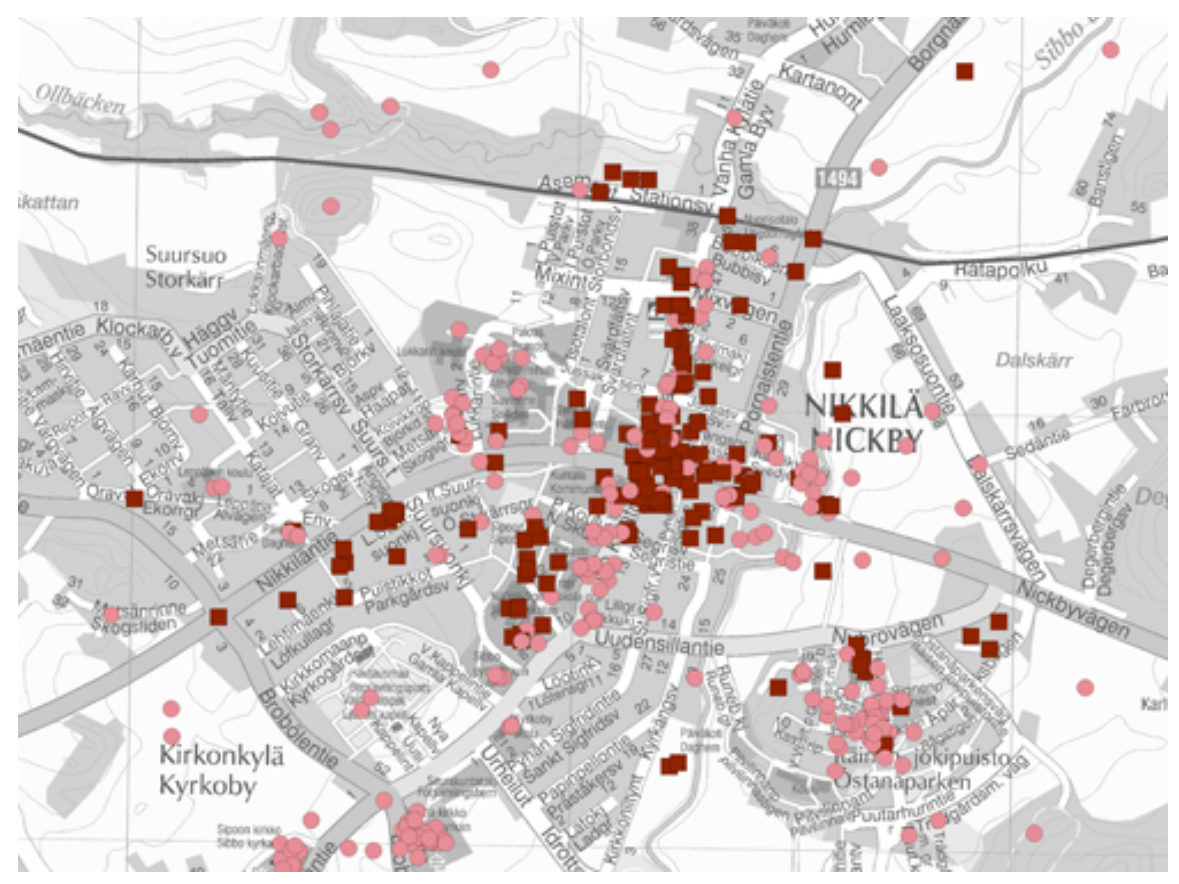

Figure 11. Map indicating sites that enhance or weaken the image of Nikkilä. Source: Municipality of Sipoo

Interactions between different actors (e.g., local inhabitants, third sector representatives, and municipal representatives from different sectors) organized during the planning stage contributed positively to the design of the survey. The results of the early workshop and feedback from beta testing were critical for the planning of the survey content. In our view, participation by different stakeholders in the planning of the survey injected the project with the desired bottom-up thinking, although the survey as such is an administratively driven method.

The survey received both positive and negative feedback. The greatest problems for the respondents were related to the usability of the map tools and the extent of the survey. The overall reception was quite positive, however, and judging by the extent and good quality of the collected data, it is our estimate that the survey functioned as intended. 


\section{Conclusions}

Cultural planning is a new practice in Finland. Its differences vis-à-vis urban planning are not easy to define. In our view, cultural planning differs from participatory urban planning in that it has people and activities at its core instead of places. Moreover, cultural planning is essentially a bottom-up method (Mercer 2006), whereas participatory planning tends to be administratively driven and usually does not include residents in the planning process as proactive agents. The topdown approach tends to be dominant in Finnish planning regimes, and the integration of bottom-up approaches into planning processes is difficult. Further study is needed regarding practical ways to combine genuine resident-orientation with administratively oriented operations.

A web map survey is fundamentally an administratively driven method. As a research method, a survey treats residents and their opinions as objects. The 'citizen orientation' of a survey can be increased by planning the survey collaboratively with different actors: local residents, entrepreneurs, and representatives from the municipal administration. Interactive planning of a cultural mapping survey is important because the results of the survey are significantly affected by the type of questions it asks. The integration of local residents in survey planning is not easy, however, because a survey is conceptually quite abstract. In our research, we used a game-like collaboration method tailored for the purpose, which facilitated interaction and discussion.

The map-based nature of a survey can be seen both as an asset and a weakness. From the viewpoint of cultural mapping, the fact that the survey is map-based may be a problem, because cultural resources are not exclusively tangible sites, they can also be non-geographic values or phenomena (such as memories and history, or experiences of art). That being said, a very large proportion of cultural resources is nevertheless associated with some physical site in one way or another. The data that was mapped in the survey can be used in planning with the aid of GIS software.

A map survey is a functional tool for cultural mapping. The Harava service enabled us to collect abundant and qualitatively sound data that allowed the identification of cultural resources and development areas in Nikkilä. Apart from a map survey, however, a cultural mapping project must also use other methods to complement the data. A map survey allows sizable and high-quality data to be collected, but the respondents can never represent all the groups in a given area, and in this article we confine our discussion to the case of Nikkilä. The study also included complementary methods such as art exhibitions and art projects, as well as workshops for different age groups. The mutually complementary data gathered through these different methods must also be integrated into the analysis.

One challenge to the analysis of map survey results is the changing of the survey area itself. Analysis is time-consuming, and if the area changes rapidly, the data are soon no longer up to date. Repeating the survey at regular intervals would provide a temporal perspective on the area under study. In our view, cultural mapping should be a continuous process that permits the assessment of the development of cultural resources over time as a result of planning actions.

The results of a map survey or a cultural mapping project do not represent a final answer or end result: they must instead be seen as discussion openers. We are convinced that, by analyzing the results of the survey interactively, we were able to produce a comprehensive account of the cultural resources and development areas in Nikkilä. Everywhere that we have presented the maps, the 
ensuing discussion has opened up new perspectives on the survey results and the development of Nikkilä. The analysis of the results of the cultural mapping of Nikkilä in Sipoo continues in interaction with various stakeholders. As themes for further research, we have identified the methods of collaborative analysis of collected data, and the integration of tools of cultural mapping and of bottom-up thinking into our administratively driven planning system.

\section{References}

Bianchini, F. \& Ghilardi, L. (2007). Thinking culturally about place. Place Branding and Public Diplomacy, 3(4): 280-286.

Ghilardi, L. (2011, February). True to place: Embedding cultural distinctiveness in place making in European cities. Municipal World, pp. 21-24.

Kahila, M. \& Kyttä, M. (2009). SoftGIS method as a bridge builder in collaborative urban planning. In S. Geertman \& J. Stillwell (eds.), Planning Support Systems: Best Practices and New Methods (pp. 389411). Houten: Springer.

Kindon, S., Pain, R. \& Kesby, M. (2007). Participatory Action Research: Origins, approaches and methods. In S. Kindon, R. Pain \& M. Kesby (eds.), Participatory Action Research Approaches and Methods: Connecting People, Participation and Place (pp. 9-19). Oxon, U.K.: Routledge.

Finlex. (1999). Maankäyttö- ja rakennuslaki (Land Use and Building Act www.finlex.fi/fi/laki/ajantasa/1999/19990132 [15 November 2013]

Mercer, C. (2006). Towards an architecture of governance for participatory cultural policy making. Paper prepared for “Active Citizens - Local Cultures - European Politics: Barcelona Working Meeting,” 22 September 2006, Barcelona, Spain.

Staffans, A., Rantanen, H. \& Nummi, P. (2010). Local Internet forums: Interactive land use planning and urban development in neighbourhoods. In C. Nunes Silva (ed.), Handbook of Research on ePlanning: ICTs for Urban Development and Monitoring (pp. 80-102). IGI Global.

Vartiainen, K., Nieminen N. \& Tanskanen T. (2013). Living environment information services - enhancing the collaboration between authorities and the citizens. Proceedings REAL CORP 2013 Tagungsband. 20-23 May 2013, Rome, Italy. 